\title{
Research on Yunnan Province's Path of Energy Sustainable Consumption under "One Belt and One Road"
}

\author{
Linlin Liang* \\ International business school \\ Yunnan University of Finance and Economics \\ Kunming, China \\ 279653205@qq.com
}

\author{
Qicheng $\mathrm{Lu}$ \\ Business school \\ Yunnan University of Finance and Economics \\ Kunming, China \\ 317404322@qq.com
}

\begin{abstract}
Energy and environmental problems have become two major problems in the world. Compared with the energy consumption level of the whole country, the energy consumption of Yunnan 100 million yuan is significantly higher. As the industrialization of Yunnan province to the middle and later on, the energy supply and demand contradictory intensifies, leading to the province's economic and social development of resource constraints and environmental pressures, constitutes a threat to the sustainable development. Therefore, face and solve many problems of the energy in Yunnan, in Yunnan province energy system and thorough research on the sustainable consumption issue is both the needs of the development of theory, but also solve the practical problems are urgently needed. This topic research based on the needs of economic sustainable development, on the basis of analyzing energy consumption situation of Yunnan province, puts forward the sustainable consumption energy resources and environment in Yunnan province under the restriction of the implementation of the path, in order to energy consumption policy adjustment and to provide a theoretical basis.
\end{abstract}

Keywords-resource environment constraint; energy sustainable consumption; realize the path

\section{INTRODUCTION}

Energy is the important material basis for human survival and production. Rely on a large amount of energy consumption in China, and promote the rapid growth of the economy, but also pay a high price: the extensive development mode makes environmental problems appeared in our country in recent years, also make China's economic growth is more and more close to the border of the energy constraints. Energy and environmental problems have become two major problems in the world. Too fast global energy resources, energy resources consumption and environmental quality deterioration in global energy and environmental problems, such as, energy and environment problem has become the economic development that cannot be ignored and avoided in the process of the two big problems [1].

Economy, resources and environment are an inseparable system. Economic and social development is more dependent on resources and environment and constrained by it. If we

*Corresponding author cannot change the traditional mode of energy consumption, it is bound to aggravate the shortage of energy and damage to the environment and affect the sustainable development of the economy. Much starker choices-and graver consequences-in planning outline, points out that in the face of increasingly strengthening resources and environment constraints, must strengthen the consciousness of crisis and accelerate the construction of resource saving, environment friendly modes of production and consumption patterns, enhance the capacity of sustainable development, improve the level of ecological civilization. Therefore, as the energy bottleneck of economic development, environmental bearing capacity limited resources and environment constraints such as increasing, looking for the change of the energy consumption path, explore under the restriction of resources and environment to meet the requirements of sustainable development of energy consumption is the top priority.

With the advance of industrialization in Yunnan province, the energy constraints of Yunnan's economic development are becoming more and more obvious. Since 2000, the consumption demand for energy in Yunnan has increased at an alarming rate. The annual average growth rate of energy consumption has reached $11.2 \%$, and the average energy consumption elasticity coefficient has reached 1.29. As a result, the supply of coal, electricity, oil and other energy products is still full of tension despite the rapid growth of energy production in the province in recent years. The contradiction between supply and demand of energy intensifies, which leads to the increase of resource constraint and environmental pressure of economic and social development in the whole province, which poses a threat to the sustainable development of the whole province.

Yunnan's economic development level in the country is in a backward position. Compared with the energy consumption level of the whole country, the energy consumption of Yunnan 100 million yuan is significantly higher. The energy problem in Yunnan province is no longer the problem of the development of energy industry itself and the imbalance of supply and demand in the industry, but it has already involved a series of important issues such as environment and social sustainable development. Therefore, face and solve many problems of the 
energy in Yunnan, in Yunnan province system and thorough research on the energy consumption issue is not only the needs of the development of theory, but also is an urgent need to solve real problem. Only by solving the relationship between energy consumption and energy and economy can we solve a series of major problems, such as scale, speed, quality and sustainable social development of Yunnan's economy. The 12th five-year plan in Yunnan province, stressed that must highlight the ecological construction and environmental protection, speed up the construction of a resource-conserving and environment-friendly society, promote economic and social development in harmony with the population resources and environment, enhance the capacity of sustainable development. Based on this, how to solve the relationship between the economic development and energy consumption and maintain Yunnan national economy sustained, rapid, coordinated and healthy development, is a major problem facing the current economic development in Yunnan province.

\section{LITERATURE REVIEW}

\section{A. Research Review on Energy Consumption under Resource and Environment Constraints}

1) Research on sustainable development under the constraint of resource environment

Leng ShuLian argues that China's economic and social development in the process of resource shortage [2], environment worsening of the constraints of the sustainable economic and social development is more and more obvious, outstanding performance for land, water, energy, mineral resources such as insufficient supply and ecological carrying capacity and the sharpening contradictions between the economic and social sustainable development. Yu Bo, such as the endogenous growth model based on R\&D [3], built at the same time considering the depletion of energy resources, environmental threshold limit and environmental sustainable growth model of governance cost, using the optimal control method to discuss the model of balanced growth, and on the basis of the solution to further discuss the normative characteristics necessary for sustainable development.

2) Research on the relationship between energy consumption and sustainable development

In the research field of energy consumption, there are many researches on the relationship between energy consumption and economic growth, but the study on the integration of resource and environmental factors into relevant analysis models and frameworks is less. With resources and environment problem is becoming more and more serious, many scholars began to realize the importance of resources and environment constraints, but the understanding of the original just as economic development an explanation about the relationship between energy and environment, lack of system research. The analysis of resource and environmental factors into economic development is put forward after the concept of sustainable development.

Domestic scholars in the study of energy constraint problem, application of science and technology progress contribution theory, on the basis of the necessary analysis, it is concluded that energy constraint to sustainable economic development has a role or explore ways to ease constraints. At the same time, there are many researches on the integration of energy resources into economic growth model, including the introduction of energy as a new variable into Cobb-Douglas production function [4][5].

\section{B. Overview of Research on Energy Sustainable Consumption}

The United Nations environment program defined sustainable consumption: "provide services, and related products to meet basic human needs, improve the quality of life, at the same time minimizing the use natural and toxic material, so as to not endanger offspring." Based on the above definitions, sustainable consumption is defined as: "a consumption activity that meets the needs of the current generation without compromising the needs of future generations". In 2001 the United Nations environment program again to explain of sustainable consumption, think sustainable consumption covers in order to satisfy the basic needs of life, to ensure the sustainable development of human individual generation, while reducing environmental damage to human health hazards such as target which is necessary for the sustainable the characteristics of the series of ends and means. It is understood sustainable consumption as the consumption that can meet the needs of contemporary consumption development without the ability of future generations to meet their consumption development needs. It can be seen from the view of the above scholars that although scholars have different perspectives and different priorities, they all embody the core principles of sustainable consumption in the inter-generational equity. At the same time, it also reflects that sustainable consumption includes two important ideas: sustainable production consumption and sustainable living consumption. Sustainable consumption conference pointed out that the sustainable consumption connected from the raw material extraction, pretreatment, manufacturing, product life cycle to influence the purchase, use and final disposal of the factors such as link all of the component, and each link exist various effects to the environment, so can't understand and treat sustainable consumption in isolation.

Thus, sustainable production consumption and sustainable living consumption are inseparable parts of sustainable consumption, only a single any part can achieve sustainable consumption. However, due to the differences between the two consumers, there must be differences in the way of consumption and the influencing factors. In particular, sustainable production consumption takes enterprises and social groups as consumers. And sustainable living consumption is carried out by individuals or families. Therefore, sustainable consumption research not only needs to be carried out from the whole point of view, but also is necessary to carry out independent research on sustainable production consumption and sustainable living consumption.

The research on sustainable consumption started from the holistic exploration of the impact of the proposals in the sustainable consumption symposium against the proposals of isolation and fragmentation of sustainable consumption. This kind of research aims to analyze the causes of global unsustainable consumption and explore the ways to realize 
sustainable consumption. In Canada in 2003 at the international academic seminar, scholars have comprehensively analyzed the cause of the global resources crisis, points out that the rapid population growth is only part of the reason for the environmental degradation, the developed countries in northern citizen excessive consumption of resources and increase the demand for resources in developing countries also have a major impact on global resources crisis. On the basis of the analysis of the connotation of the sustainable consumption, it is proposed improving the efficiency of consumption and changing consumption patterns, to reduce the level of consumption two ways to promote sustainable consumption [4]. Fuchs \& Lorek found in the study, improve the efficiency of consumption by reducing the resource consumption of easily for the growth of population and consumption desire inflation caused by the consumption of the total demand growth is offset, only changing consumption patterns, control the level of consumption is the basic way to realize sustainable consumption. According to this, sustainable consumption is classified as weak sustainable consumption, while the latter is strong sustainable consumption. Compared to study abroad, domestic research on the integrity of the sustainable consumption more from macro level and economics this article discusses the characteristics, influence factors of the sustainable consumption patterns and the build path of sustainable consumption patterns. As it is pointed out, to realize sustainable consumption pattern, we must strengthen institutional innovation while establishing sustainable consumption concept, and establish effective incentive and restraint mechanism [6]. In the same year, Chen also discussed the motivation of sustainable consumption from the perspective of economics, and believed that the intrinsic motivation of consumers and the external motivation interact with each other to stimulate sustainable consumption.

Despite the overall sustainable consumption under the point of view of research and practice have achieved certain results, but progress is slow, sustainable consumption governance of global resources consumption during the sustainable consumption management not only reduced, but continue to rise[7][8][9]. These data once again illustrate the deficiencies of the pure holistic study. Of course, focusing on weak sustainable consumption is also an important reason why Madrid's remarkable governance effect is difficult to achieve. The sustainable consumption patterns and their transition way is the first priority, but given the nature of the consumption pattern, the people's consumption behavior norms and operation mechanism, the embodiment of the law, the study of sustainable consumption patterns necessary to sustainable consumption behavior research as a starting point.

\section{ANALYSIS OF ENERGY CONSUMPTION IN YUNNAN PROVINCE}

Energy is the engine of national economic development and the material basis of human civilization. It is one of the prerequisites for the realization of modern society. Yunnan province is rich in energy resources, but not high in energy. Chemical industry, nonferrous metals, cement, sugar, tobacco industry are the major energy users in Yunnan, and the industry has different characteristics with the country. Since the implementation of the "multiplier plan" in Yunnan province in 2005, these industries have achieved rapid development, and energy shortage has become a direct restriction factor for Yunnan's economic development. In recent years, the GDP of Yunnan province has been increasing steadily, and the efficiency of energy utilization is obviously low. In the long run, it will be the sustainable development of Yunnan's economy. Therefore, it is necessary to systematically study the current situation and effect of energy consumption in Yunnan, and provide the basis for the sustainable energy consumption of Yunnan province.

\section{A. The Connotation of Energy Sustainable Consumption in Yunnan Province}

\section{1) The connotation of sustainable consumption}

Since the topic of "sustainable consumption" was formally put forward at the Oslo symposium in 1994, there has been extensive discussion and research. The United Nations environment program in Nairobi policy factors of the sustainable consumption report, sustainable consumption is defined as "volunteer service and related products to meet basic human needs, improve the quality of life, is in the use of natural resources and toxic materials at least at the same time, make the service or product life cycle and pollution of waste generated, at least not endanger offspring needs."

2) Research on sustainable consumption of carbon sequestration perspective

Carbon emissions are a general term for greenhouse gas emissions. Most scientists and governments acknowledge that greenhouse gases have been and will continue to bring disaster to earth and humanity. And carbon emissions as a measurable in the process of production, monitoring indicators, in the process of sustainable development, set up a clear boundaries, benchmarking, to regulate, restrict the burning of fossil energy use, to slow down is caused by excessive use of energy resources, environmental adaptation, and may cause the intergenerational unfairness.

Since national industrial development, carbon emissions increase, as major emitters of government and enterprise, and at the same time as the science and technology developers and users, should actively change economic growth mode, and the allocation of resources structure, increasing scientific research strength, energy efficiency, active development and use of clean energy, reduce carbon emissions. The government needs to actively optimize the energy structure.

Sustainable consumption is the consumption of the coordinated development between man and society, man and nature. Consumers, whether or not they are aware of it, have carbon emissions in every aspect of their lives. With the continuous improvement of human civilization, represents a more healthy, more natural, more secure low-carbon life has entered people's life, China's large population base, the sum of individual carbon also produces a deep influence to the society. Carbon emissions, housing structures and new technologies are also important for carbon emissions. 


\section{B. Analysis of Yunnan Energy Consumption}

In recent years, Yunnan's economic and social development situation is good, as the "area" is put forward, and Yunnan in China to southeast of Asia, South Asia important channel of the land, has become China and southeast Asia, South Asia regional economic cooperation of important channel.

Yunnan province is rich in energy resources, but not high in energy. Chemical industry, nonferrous metals, cement, sugar, tobacco industry are the major energy users in Yunnan, and the industry has different characteristics with the country. Therefore, it is necessary to systematically study the law of energy consumption and energy efficiency in Yunnan, and provide the basis for formulating targeted energy saving countermeasures.

\section{1) Current situation of total energy consumption}

The province's energy consumption showed a trend of rapid growth, the energy production is not enough to ensure the province's energy consumption, although since 2010, energy production is higher than that of the total consumption, but for flat state.

\section{2) Analysis of elasticity coefficient of energy consumption} in Yunnan province

Energy consumption Elasticity coefficient (Elasticity coefficient of energy consumption) is reactive energy consumption growth rate and proportion relationship between the national economic growth indicators, belong to the acceleration ratio, is commonly used both the ratio of average growth seen said. If energy consumption elasticity coefficient is low, the energy needed for more cities on a country's economic growth depends on saving and enhance the investment, rather than the amount of energy saving technology shows that the country's energy efficiency is high. In the process of industrialization, the low - to middle-income period of development, economic growth, the demand for energy demand depends on the amount of energy input, and the energy consumption growth needs ahead of economic growth, energy consumption elasticity coefficient should be greater than 1; When energy consumption reaches a certain level, it should be stable and close to 1; With the progress of science and technology, to improve management and the change of industrial structure, energy consumption is declining, this is should be less than 1. Generally the energy consumption elasticity coefficient of developed countries is small, less than or close to 0.5 .

\section{3) Analysis of energy consumption structure in Yunnan} province

Energy consumption is dominated by coal, and the "high carbon" features of the economy are prominent. Compared with oil and natural gas, the $\mathrm{CO} 2$ produced by the unit of thermal coal is about $36.00 \%$ and $61.0 \%$ higher than oil and natural gas respectively. However, Yunnan lacks gas, energy consumption structure is dominated by coal, carbon dioxide emissions are high, and coal energy utilization is low, and the "high carbon" characteristics of Yunnan's economic development are very obvious.

\section{METHODS OF ENERGY SUSTAINABLE CONSUMPTION IN YUNNAN PROVINCE}

\section{A. Adjust the Energy Supply Structure}

1) With the development of electric power, the proportion of power in total energy is further improved

To improve high quality energy and a power ratio in the energy structure, can effectively improve the efficiency of energy utilization, reduce energy demand, and can significantly reduce $\mathrm{CO} 2$ emissions of greenhouse gases, such as is the effective measure to reduce energy demand and the necessary conditions. Power is a kind of important secondary energy, clean energy, hydroelectric power generation in Yunnan province has huge potential, as China's one of the major provinces and outside the guarantee cloud electricity to send at the same time, to meet their own sustained economic growth increasingly rapid consumer demand for electricity, to exert the advantages of hydropower development in Yunnan province, vigorously develop hydropower, increase input to the electricity in the province, meet the growing demand for electricity production and consumption.

2) Increase the use of oil and natural gas and increase its proportion in energy consumption

Although Yunnan province is short of oil and gas, it has a certain amount of reserves and better exploration prospects. It can introduce technology and utilize the oil and natural gas energy resources in the province to the greatest extent. On the other hand, the high quality energy in the gas is ideal, and is one of the most known cleaning chemical fuels, Myanmar's rich natural gas resources, Yunnan province, which borders Myanmar, can take advantage of the geographical conditions in Yunnan province to Burma to buy natural gas energy resources, to increase the proportion of natural gas in the total energy consumption, achieve the goal of optimizing the energy consumption structure, realize the target.

\section{3) Current situation of total energy consumption}

Renewable energy is generally a good source of green energy, and the consumption of renewable energy is largely free from environmental pollution. In the past 20 years, the development and utilization of renewable energy has not only developed greatly in China, but also become an indispensable part of our energy system. With the tension of energy situation, the development of new energy and renewable energy has received unprecedented attention from the country. The solar energy, wind energy, geothermal energy and other renewable energy resources in Yunnan province are rich in storage and have broad development prospects.

\section{B. Optimize Industrial Structure}

1) Optimize the industrial structure and vigorously develop and use clean energy

To adjust the industrial structure of Yunnan province, it is necessary to optimize the structure of the industrial sector. Adjusted to the extraction of metal, metal smelting and processing, non-metallic mineral products industry, chemical raw materials and chemicals give priority to heavy industry structure, promote industrial upgrading, strict market access, and intensify efforts to close down backward production 
facilities, make on a new path of industrialization in Yunnan province, and increasing the use of water and electricity, solar energy, wind energy, geothermal energy and other clean energy.

2) Strengthen technological innovation and use new and high technology to optimize the industry in terms of energy consumption and output

Strengthening technical innovation and references to high and new technology to improve due to technical level and poor equipment using high carbon dioxide emission factor of fossil energy use efficiency, eliminate backward production capacity, and transform traditional industries, to reduce the total energy consumption, reduce carbon emissions. In addition, the introduction of new technologies such as CCS to reduce carbon footprint and commercialize them can play a significant role in industrial optimization and emission reduction targets.

\section{Strengthen Energy Conservation Management}

We should strengthen energy conservation, reduce the growth rate and total amount of energy consumption, and achieve rapid economic growth. Low energy green (low carbon) development of growth, more emphasis on optimizing the economic structure, with energy saving technology, research and development of energy-saving products, energy saving and consumption pattern change, lead to the development of emerging industries, instead of the original rely on the traditional model of economic growth energy intensive industries.

1) Strengthen the development and promotion of energysaving technologies in key industries. Current situation of total energy consumption

For Yunnan province, the high energy consumption industries concentrated in the iron and steel, coal, building materials, chemicals, nonferrous metals, electric power industry, such as strengthening energy conservation must be in the corresponding energy saving technology development and promotion of the industry. For example, the converter negative energy steelmaking technology and regenerative combustion technology used in the steel industry; Coal chemical conversion technology and comprehensive utilization technology of coal seam methane in coal industry; In the cement industry, the new type of dry kiln decomposition technology is developed. The synthetic ammonia used in the chemical industry adopts energy saving equipment and variable pressure adsorption recovery technology, energy-saving caustic soda production technology and yellow phosphorus industry promotion furnace gas recovery and utilization technology, etc.

\section{2) Advocate energy-saving lifestyle}

It is much more difficult to guide people's way of life than to establish an energy-saving mode of production, and to overcome many existing limitations, such as Energy-saving laws and regulations, the government in energy conservation investment, energy - saving infrastructure and so on. So largescale propaganda, education, training, the introduction of advanced, environmental protection and sustainable development of social development concept and life concept, change the public consumption consciousness, make frugal consumption idea in every public's heart deeply, clear based on the new development view of social development direction, encourage social reasonable consumption choices.

\section{Strengthen the Design and Management of Energy Planning in Urban Areas}

On the premise of reasonable technical and economic reasoning, we should accelerate the formulation of relevant laws and regulations on energy development strategy and emission reduction targets. At the same time, the relevant departments of Yunnan province should supervise urban areas to speed up the development of energy development strategies and emission reduction targets in the region and timely guide and revise them. In addition, the related department of Yunnan province should be with the provincial resources and technology advantages, the urban areas and between different departments of the staff to strengthen the new energy, energy saving technology consulting and information service, foster and standardize the market for renewable energy technologies. We will strengthen the construction of new energy and energy conservation technology service centers, and carry out technical exchanges among various channels, training of energy management personnel, key energy-consuming equipment and process operators. To carry out cooperative development, research and production of energy-saving products.

\section{CONCLUSION}

Economy, resources and environment are an inseparable system. Economic and social development is more dependent on resources and environment and constrained by it. As the industrialization of Yunnan province to the middle and later on, the energy supply and demand contradictory intensifies, leading to the province's economic and social development of resource constraints and environmental pressures, constitutes a threat to the sustainable development. The energy consumption in Yunnan province has already touched on a series of important issues such as environment and social sustainable development. The 12th five-year plan in Yunnan province, stressed that must highlight the ecological construction and environmental protection, speed up the construction of a resource-conserving and environment-friendly society, promote economic and social development in harmony with the population resources environment, enhance the capacity of sustainable development. Therefore, how to achieve sustainable energy consumption is a major problem facing Yunnan's economic development.

\section{ACKNOWLEDGMENT}

The authors thank other members of the research group for helpful, valuable, and constructive comments and suggestions on earlier versions of this paper. The paper is supported by the National Natural Science Foundation of China (No.71663057). 


\section{REFERENCES}

[1] V. Alcantara, Duarte, R.."Comparison of energy intensities in European Union countries. Results of a structural decomposition analysis”, Energy Policy, Vol. 32, pp.177-189, Feb. 2014.

[2] Leng Shulian, Leng Congzong. Research on Resource and environmental constraints and sustainable development, the developments[J].pp.2007.1

[3] Yu Bo, Li Yongliang, Chi Chunjie. The endogenous model of sustainable economic growth considering energy consumption and pollution control [J]. Journal of Management Science.pp.12-17, April, 2006.

[4] Wang Haijiian. Depletion of resources, R\&D and endogenous economic growth models $[\mathrm{J}]$. Application of system engineering theory and method.pp.38-42, March, 1999.
[5] Wei Weixian, Wang Feng. Energy intensity convergence: a test of both developed and developing countries $[\mathrm{J}]$. China's population, resources and Evnvionment.pp.43-51,March, 2011

[6] R. Hannesson, "Energy Use and GDP Growth, 1950-97". OPEC Review, Vol. 26, No. 3, pp. 215 233.2016

[7] M. Liop, L. Pie "Input-output analysis of alternative policies implemented on the energy activities: An application for Catalonia", Energy Policy, Vol. 36, pp. 1642-1648, May,2008

[8] J. Ramos-Martin. Historical analysis of energy intensity of Spain: from a conventional view to an integrated assessment $[\mathrm{J}]$. Population and environment, pp.281-313, March, 2001.

[9] Sin Cherng Lee, Denny Kok Sum Ng, Dominic chwan Yee Foo, Raymond R. Tan. Extended pinch targeting techniques for carbonconstrained energy sector planning[J]. Energy,pp.60-67,Jan. 2013 